\title{
Aerosol single scattering albedo retrieved from ground-based measurements in the $\mathrm{UV}$ and visible region
}

\author{
V. Buchard, C. Brogniez, F. Auriol, and B. Bonnel \\ Laboratoire d'Optique Atmosphérique, CNRS/UMR 8518, Université Lille 1 - Sciences et Technologies, Lille, France
}

Received: 16 July 2010 - Published in Atmos. Meas. Tech. Discuss.: 30 July 2010

Revised: 15 December 2010 - Accepted: 17 December 2010 - Published: 3 January 2011

\begin{abstract}
Estimates of Aerosol Single Scattering Albedo (SSA) from ground-based spectral measurements in the UVvisible are conducted at Villeneuve d'Ascq (VdA) in France. In order to estimate this parameter, measurements of global and diffuse UV-visible solar irradiances performed under cloud-free conditions since 2003 with a spectroradiometer operated by the Laboratoire d'Optique Atmosphérique (LOA) are used. The technique consists in comparing the measured irradiance values to modelled irradiances computed for various SSA. The retrieval is restricted to the 330$450 \mathrm{~nm}$ range to avoid ozone influence.
\end{abstract}

For validation purpose, the retrieved values of SSA at $440 \mathrm{~nm}$ are compared to the ones obtained from sunphotometer measurements of the AERONET/PHOTONS network available on the LOA site. The results are rather satisfying: for the period 2003-2006 the Root Mean Square (RMS) of the differences is about 0.05 , this value is within the uncertainty domain of retrieval of both products. Distinction between days characterized by different aerosol content, by means of the aerosol optical thickness (AOT) retrieved from ground-based measurements at the same wavelength, shows that the comparisons between both products are better when AOT are higher. Indeed in case AOT are greater than 0.2 , the RMS is 0.031 compared to 0.060 for days with an AOT lower than 0.2. The SSA estimated at 340 and $380 \mathrm{~nm}$ from ground-based spectra are also studied, though no validation can be carried out with sunphotometer data $(440 \mathrm{~nm}$ is the shortest wavelength at which the SSA is provided by the network). The good comparisons observed at $440 \mathrm{~nm}$ can let assume that the SSA retrieved from spectroradiometer measurements at the two other wavelengths are also obtained with a good confidence level. Thus these values in the UV range can be used to complete aerosol data provided by

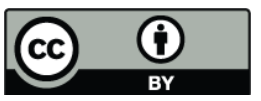

Correspondence to: V. Buchard (virginie.j.buchard-marchant@nasa.gov)
AERONET/PHOTONS at VdA. Moreover they can be used for a best knowledge of the aerosol absorption that is necessary to quantify the error on surface UV irradiances estimated from satellites.

\section{Introduction}

Beside geographical and temporal factors, several atmospheric parameters other than ozone influence the quantity of UV radiation reaching the Earth's surface. The most important are clouds and aerosols. Since several years aerosols receive a particular attention regarding their influence on climate, through both direct and indirect effects (Forster et al., 2007). The influence of atmospheric aerosols on radiation is not fully understood due to their high spatial and temporal variability. The aerosol studies related to aerosol forcing have been conducted mainly over the visible spectrum. However, some progress has been made in recent years to understand the effects of aerosols on ultraviolet UV radiation (WMO, 2007). In addition to the Aerosol Optical Thickness (AOT), a detailed knowledge of the Single Scattering Albedo (SSA) (i.e. the ratio of scattering coefficient to extinction coefficient), which provides information about the absorbing properties of the aerosols, is necessary to quantify the impact of aerosols on climate. Moreover a good knowledge of the regional characteristics of the SSA would allow decreasing the errors in the surface UV irradiance derived from space-borne measurements (Arola et al., 2009; Ialongo et al., 2010).

The AERONET/PHOTONS network (Holben et al., 1998) has been developed to determine aerosol optical properties but the shortest wavelength at which the SSA is restituted is $440 \mathrm{~nm}$, i.e. in the visible. The SSA parameter is difficult to estimate in the UV range and even in the visible close to the UV due to rather large uncertainties existing on ground-based and space measurements in this wavelength

Published by Copernicus Publications on behalf of the European Geosciences Union. 
range (Torres et al., 1998; Petters et al., 2003; Bais et al., 2005; Corr et al., 2009). Nevertheless, several methodologies using ground-based spectral measurements associated with radiative transfer model calculation have been developed (Petters et al., 2003; Bais et al., 2005; Krotkov et al., 2005; Kazadzis et al., 2010) to determine a SSA averaged over the vertical column, and we have conducted such a retrieval.

The spectroradiometer performing spectral UV irradiance measurements in VdA used in this study is described in Sect. 2 along with the methodology used to derive the SSA from these ground-based measurements.

Section 3 reports comparisons between the previous product at $440 \mathrm{~nm}$ and the SSA derived at the same wavelength from measurements of AERONET/PHOTONS sunphotometers located close to the spectroradiometer. SSA values retrieved from the spectra at shorter wavelengths are also presented, extending the spectral variations of the SSA provided by AERONET/PHOTONS towards the UV. Section 4 reports the conclusions.

\section{Instruments and methodology}

\subsection{Ground-based instrument}

The instrument used in this study is a Jobin-Yvon HD10 spectroradiometer located in Villeneuve d'Ascq $(\mathrm{VdA})$ on the roof of the laboratory building $\left(50.61^{\circ} \mathrm{N}, 3.14^{\circ} \mathrm{E}\right.$, $70 \mathrm{~m}$ a.s.1.). This site is typical of a flat region near a city in the north of France.

The spectroradiometer scans the wavelength range from 280 to $450 \mathrm{~nm}$ with a sampling step of $0.5 \mathrm{~nm}$ and its spectral resolution is about $0.7 \mathrm{~nm}$. A single spectral scan takes about 6 min. Calibration is performed every 3 months with two standard lamps traceable to NIST (National Institute of Standard lamp and Technology) and NPL (National Physical Laboratory), and each spectrum is corrected of the wavelength misalignment via a software tool developed at LOA (Houët, 2003). The irradiance expanded uncertainty (coverage factor $k=2$ ) is about $7 \%$ at $320 \mathrm{~nm}$ and about $5 \%$ at $400 \mathrm{~nm}$ for a high irradiance level and 9\% and 7\% respectively for a low irradiance level (Houët, 2003). The instrument has been intercompared with the QASUME spectroradiometer (Quality Assurance of Spectral Ultraviolet Measurements in Europe) in September 2004 (Gröbner et al., 2006).

Since the implementation of a shadow disc in early 2003 , the spectroradiometer performs alternately scans of the global and of the diffuse irradiance every $15 \mathrm{~min}$. The use of a shadow-disc to hide the sun during the diffuse irradiance measurement leads to a measured value slightly smaller than the true value. To account for the bias, a mean correction is performed in the data processing by using radiative transfer computations (Houët, 2003). The difference between the global spectral irradiance and the mean of the two diffuse spectral irradiances, performed $15 \mathrm{~min}$ apart, enables to derive the direct spectral irradiance. The time lag introduces some errors depending on the aerosol content and on the variation of the SZA during the registration of the spectra. The error is estimated and corrected in the processing. A careful analysis has shown that the use of the shadower adds a negligible uncertainty on the direct irradiance data, reaching only $1 \%$ for SZA $>60^{\circ}$ (Houët, 2003; Brogniez et al., 2008). We have limited our SSA retrievals for SZA $<65^{\circ}$. To ensure that clear sky conditions are met during the three scans, the 3-min period measurements of a YES UVB-1 radiometer, close to the spectroradiometer, are examined.

On clear sky conditions, the analysis of the direct irradiance is used to derive the spectral AOT in the $330-450 \mathrm{~nm}$ range with uncertainties varying from about 0.03 at $440 \mathrm{~nm}$ for $\mathrm{SZA}=70^{\circ}$ to 0.05 at $340 \mathrm{~nm}$ for $\mathrm{SZA}=40^{\circ}$ (Brogniez et al., 2008).

\subsection{Retrieval of the single scattering albedo}

The SSA is estimated using global and diffuse irradiance measurements as well as direct-to-diffuse irradiance ratio (dr/df). The technique consists in comparing the measured quantities with modeled ones as proposed by Petters et al. (2003) and Bais et al. (2005).

The modeled irradiances are computed using a radiative transfer (RT) code (DISORT, DIScret Ordinates Radiative Transfer; Stamnes et al., 1988) for various SSA values. The SSA values range from 0.60 to 1 , with a step of 0.01 . Following the study of Bais et al. (2005), we select the SSA for which the modelled and the measured quantities agree to within $1 \%$. Generally, for the three quantities, more than one SSA value can satisfy this condition, leading to a SSA range.

The other input parameters used in the RT model are the mid-latitude temperature and pressure profiles and the aerosol parameters. The spectral AOT is derived from the spectroradiometer measurements, the asymmetry parameter $(g)$ is supposed to be spectrally constant. We choose 0.7 following the studies of Madronich (1993), who found $g$ varying between 0.6 and 0.8 in the UV wavelength range, and of Bais et al. (2005), who found $g$ around 0.7 for urban aerosols. Moreover this value is consistent with an analysis of AERONET/PHOTONS data (level 1.5) showing a mean value of $0.70 \pm 0.02$ at $440 \mathrm{~nm}$ in VdA. The surface albedo is supposed equal to 0.02 for all wavelengths (Feister and Grewe, 1995). The accuracy on the retrieved SSA results from the uncertainties existing on these input parameters and on the measured irradiances. Based on model calculations, the effects of $g$ and the surface albedo variations on SSA retrieval have been studied. We found that the variation of $g$ between 0.68 and 0.72 leads to a slight variation of the SSA value, about 0.01 . The same conclusion was observed for a surface albedo value varying between 0.01 and 0.04 . The resulting uncertainty for both effect is about 0.02 at $380 \mathrm{~nm}$. SSA uncertainties have been estimated for two SZA 

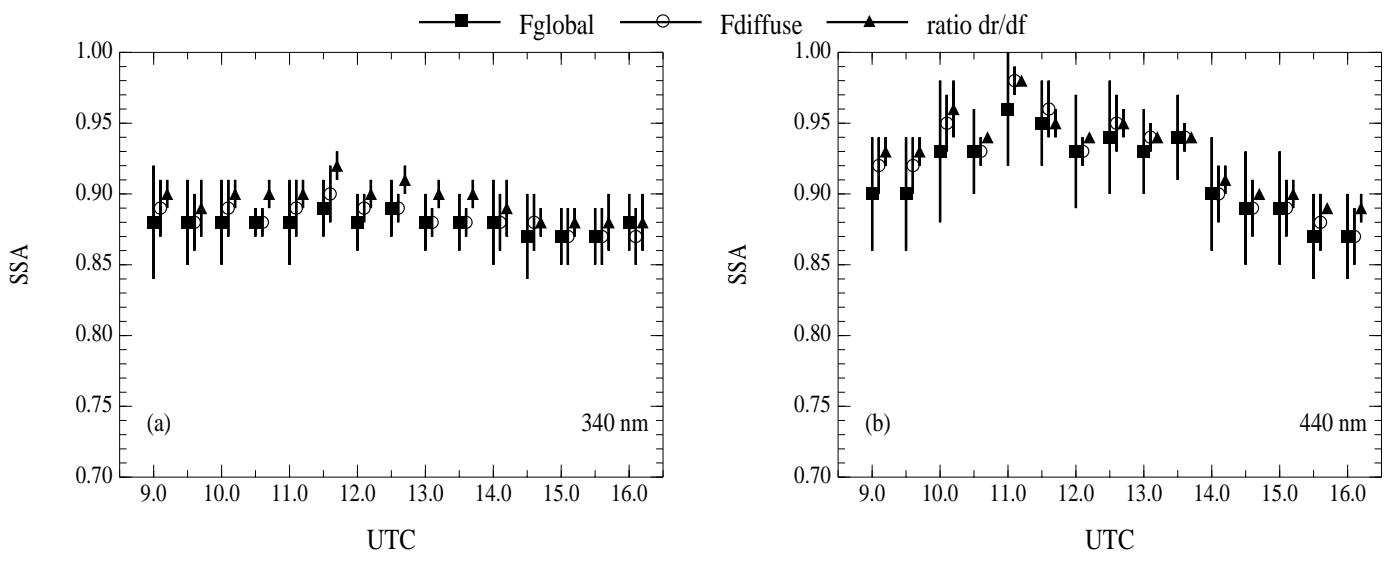

Fig. 1. Daily variations of SSA retrieved from global (square), diffuse (circle) and the direct-to-diffuse ratio (triangleup) measured by the spectroradiometer on 11 September 2006: (a) at $340 \mathrm{~nm}$; (b) at $440 \mathrm{~nm}$. Vertical bars correspond to the standard deviation around the mean SSA computed over $5 \mathrm{~nm}$ around the central wavelength (see text).

cases using modelling with two AOT values. The results at $380 \mathrm{~nm}$ for the three quantities (global, diffuse and ratio $\mathrm{dr} / \mathrm{df}$ ) are reported in Table 1 . The accuracy on the retrieved SSA depends on the amount of aerosol and for the global quantity, on the SZA, and it appears that the three quantities are less sensitive to changes in SSA at small AOT and for the global quantity also at small SZA. Moreover, the $\mathrm{dr} / \mathrm{df}$ ratio provides the better accuracy in the estimation of $\mathrm{SSA}, \Delta(\mathrm{SSA}) \approx 0.05$. Similar conclusions were obtained at 340 and $440 \mathrm{~nm}$. These results are consistent with those retrieved by Bais et al. (2005) and Petters et al. (2003).

As discussed in Brogniez et al. (2008), important high frequency variations appear in the AOT spectrum deduced from the spectroradiometer measurements, especially near Fraunhofer lines. To remove these rapid oscillations a triangular smoothing over $4 \mathrm{~nm}$ is performed (Brogniez et al., 2008). Few oscillations remain, more or less pronounced depending on the extraterrestrial spectrum used. To reduce the error on the retrieved SSA linked to these AOT oscillations, a SSA average is computed over $5 \mathrm{~nm}$ around each wavelength, (i.e. $2.5 \mathrm{~nm}$ before and after each wavelength). Figure 1 shows an example of diurnal variations of the SSA obtained on a cloud-free day around $340 \mathrm{~nm}$ (Fig. 1a) and $440 \mathrm{~nm}$ (Fig. 1b), the errors bars are the standard deviations of the SSA. As expected from the results in Table 1, the dispersion is larger when global or diffuse measurements are used, meaning that the SSA is worse estimated when using these two measurements rather than the $\mathrm{dr} / \mathrm{df}$ ratio. Thus, in the following we have only considered the SSA derived from this latter quantity.

Moreover, Brogniez et al. (2008) have noticed that the AOT at $440 \mathrm{~nm}$ obtained with the Thuillier et al. (2003) spectrum (referred to as TRS in the following) agree better with the AOT obtained from AERONET/PHOTONS measurements, but that the oscillations are larger than when using the reconstructed high resolution spectrum, KP320at3,
Table 1. Estimated uncertainty on the SSA retrieved from spectral global and diffuse irradiances and from the direct-to-diffuse irradiance ratio (dr/df) at $380 \mathrm{~nm}$ for two AOT, at two SZA. Similar results were obtained at 340 and $440 \mathrm{~nm}$.

\begin{tabular}{llllllll}
\hline Quantity & \multicolumn{2}{c}{ Global irradiance } & \multicolumn{2}{c}{ Diffuse irradiance } & \multicolumn{2}{c}{ Ratio dr/df } \\
\hline AOT & 0.2 & 0.4 & 0.2 & 0.4 & 0.2 & 0.4 \\
\hline$\Delta(\mathrm{SSA})$ & & & & & & \\
$\mathrm{SZA}=30^{\circ}$ & 0.16 & 0.09 & 0.08 & 0.05 & 0.06 & 0.04 \\
$\mathrm{SZA}=60^{\circ}$ & 0.13 & 0.07 & 0.08 & 0.05 & 0.06 & 0.04 \\
\hline
\end{tabular}

provided in the SCHICrivm software (Slaper et al., 1995), (referred to as SRS in the following). Thus, given the sensitivity of SSA to the AOT we have constructed a "new spectrum" in the spectral range $400-450 \mathrm{~nm}$ with the SRS resolution and the TRS radiometry. For that purpose we multiplied the SRS spectrum by 0.95 in order to reach the TRS radiometry. The coefficient 0.95 is a mean value over $400-450 \mathrm{~nm}$ of the ratio of both extraterrestrial spectra. The three extraterrestrial spectra are presented in Fig. 2.

The effect of the extraterrestrial spectrum on SSA retrieval at $440 \mathrm{~nm}$ is shown in Fig. 3, which present two examples of the retrieved results for two days characterized by different aerosol content. The daily mean AOT is 0.12 on the first day while it is about 0.26 on the second day. The black squares are obtained with the "new spectrum" and the blue squares are obtained with the TRS. For the first day the AOT variations obtained with both spectra are very close, there is about 0.01 difference on average (Fig. $3 \mathrm{~b}$ ). The SSA variations (Fig. 3a) exhibit the same behaviour but the values are different, about 0.04 difference on average, and the dispersion is larger with the TRS. For the other day, the AOT values differ also by about 0.01 on average (Fig. 3d) but the SSA 


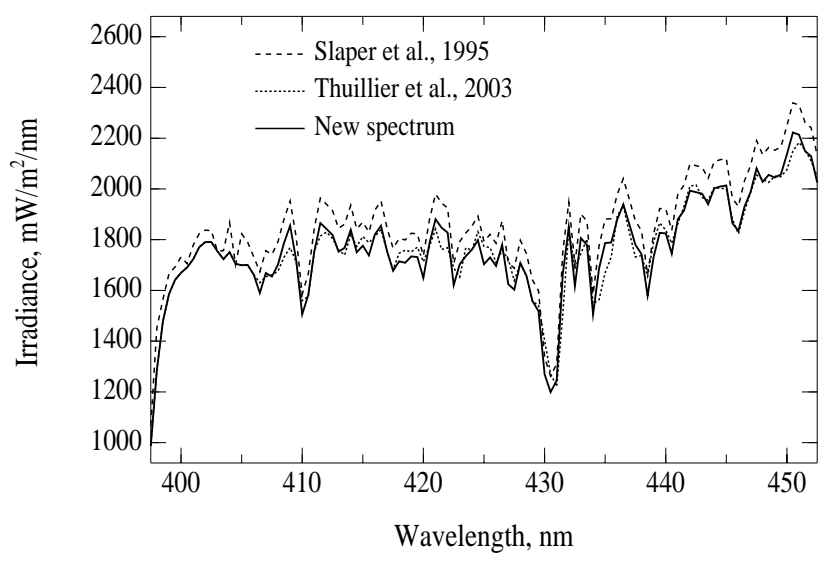

Fig. 2. Extraterrestrial spectra between 400 and $450 \mathrm{~nm}$ : Slaper et al. (1995) in dash-line; Thuillier et al. (2003) in microdash-line and the "new spectrum" constructed from both in solid-line.

values are less different, about 0.02 on average (Fig. 3c) and the dispersion is very similar for both reference spectra. So we can conclude that the choice of the extraterrestrial spectrum is important in case of low aerosol content due to the sensitivity of the SSA retrieval to the aerosol load.

\section{Applications}

The shortest wavelength at which SSA is deduced from sunphotometer measurements of the AERONET/PHOTONS network is $440 \mathrm{~nm}$. The inversion algorithm provides SSA using the sky radiance measurements along the solar principal plane and along the solar almucantar (Dubovik et al., 2000; Dubovik and King, 2000). According to these authors, the uncertainty in the retrieved SSA varies between 0.03 and 0.07 depending on the aerosol type and loading. For urban aerosol type, the SSA retrieval accuracy is between 0.05 and 0.07 when the AOT is lower or equal to 0.2 and 0.03 when the AOT is greater than 0.2. Due to the weakness of the AOT in VdA, the AERONET/PHOTONS data used here are level 1.5 values, which are cloud-screened.

Figure 4 shows scatter plots of SSA retrieved with the spectroradiometer and with the sunphotometer on clear sky conditions, for the years 2003, 2005 and 2006 at $440 \mathrm{~nm}$. We have considered separately days with an AOT lower than 0.2 (Fig. 4a) and greater or equal to 0.2 (Fig. 4b). The number of sunphotometer's inversion in a day is generally small because of the required criteria for a good inversion (see above), which explains the small number of comparison points (101 and 59).

Accounting for the uncertainties on both products, the comparison is rather satisfying, the correlation coefficient are $r=0.85$ for days characterized by a low aerosol content and $r=0.79$ for days with AOT greater than 0.2. We can notice that points characterized by high absorption are retrieved by both photometer and spectroradiometer. When looking at the days with an AOT lower than 0.2 (Fig. 4a), differences between SSA obtained from the spectroradiometer and from photometers are generally larger, RMS is 0.060 compared to 0.031 if we consider only days with an AOT greater than 0.2 (Fig. 4b). This result confirms the difficulty to retrieve a SSA when the AOT is low.

If we consider all days (Fig. $4 a$ and b), we notice that on average the SSA retrieved from the spectroradiometer are lower than those retrieved from the sunphotometers, mean differences (spectroradiometer-photometer) being negative and equal to -0.03 for days with a low aerosol content and -0.01 for days with an aerosol content higher.

As stated in Sect. 2.2, the SSA is also retrieved at shorter wavelengths from the spectroradiometer measurements. In that case no validation via the sunphotometers can be carried out, nevertheless since the AOT inferred at 380 and $340 \mathrm{~nm}$ have been well validated against AERONET/PHOTONS (Brogniez et al., 2008), the corresponding SSA are assumed to be reliable. Figure 5a-b presents an example of the spectral dependence of the SSA retrieved from the spectroradiometer at 340, 380 and $440 \mathrm{~nm}$ combined with the SSA deduced from AERONET/PHOTONS measurements at 440, 675,870 and $1020 \mathrm{~nm}$ with their corresponding uncertainties on 29 January 2006 at 11:00 UTC and 11 September 2006 at 13:30 UTC. For the spectroradiometer they are estimated following the Table 1 and for sunphotometers they are estimated to 0.05 .

First, one can note that the spectroradiometer's SSA values at $440 \mathrm{~nm}$ are very close to sunphotometers' ones. The sunphotometer SSA values are well within the spectroradiometer uncertainty bars. One can notice also that the aerosols are more absorbent as wavelength increases on 29 January 2006 whereas the opposite is observed on 11 September 2006. Thus the aerosol spectral absorption seems to depend on the period of the year, but it depends also on the year, as confirmed in the following.

Figure $6 \mathrm{a}-\mathrm{b}$ presents the monthly means of the SSA at 340,380 and $440 \mathrm{~nm}$ for the spectroradiometer and at 440 , 675, 870 and $1020 \mathrm{~nm}$ for sunphotometers in 2003 and 2006. The same days are considered to compute the monthly mean and dispersion around the mean at each wavelength, the number of days is indicated on top of Fig. 6a-b. The SSA monthly mean values at $440 \mathrm{~nm}$ from the spectroradiometer are well within the sunphotometer dispersion bars for most of the months.

The SSA spectral dependence is more or less pronounced depending on the period of the year. For example, in January 2006 , the SSA mean value at $440 \mathrm{~nm}$ for the spectroradiometer and for the sunphotometer are equal $(0.84 \pm 0.05)$, and the value at $340 \mathrm{~nm}$ is $0.92 \pm 0.03$ compared with the value at $1020 \mathrm{~nm}$ equal to $0.72 \pm 0.10$, showing large spectral variations over the whole wavelength range. Nevertheless it must be noted that for this month the dispersions in the near infrared domain are rather large, indicating a strong 

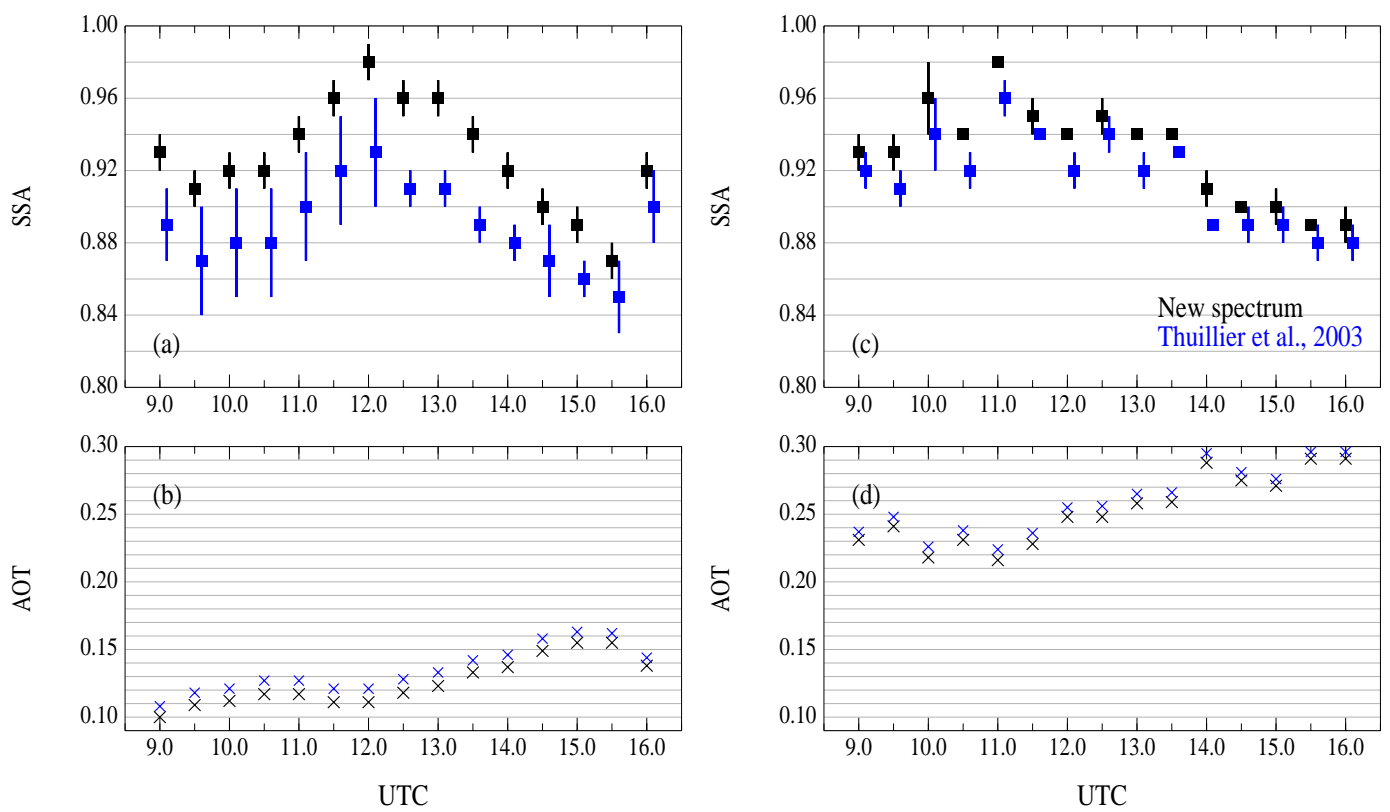

Fig. 3. Daily variations of AOT and SSA at $440 \mathrm{~nm}$ retrieved from spectroradiometer's measurements on a day characterized: (a)-(b) by a low aerosol content (12 June 2006); (c)-(d) by a high aerosol content (11 September 2006). Black symbols are retrievals with the "new spectrum", blue ones are retrievals with Thuillier et al. (2003) spectrum. Vertical bars in (a) and (c) are the standard deviations around the mean SSA computed over $5 \mathrm{~nm}$ interval.
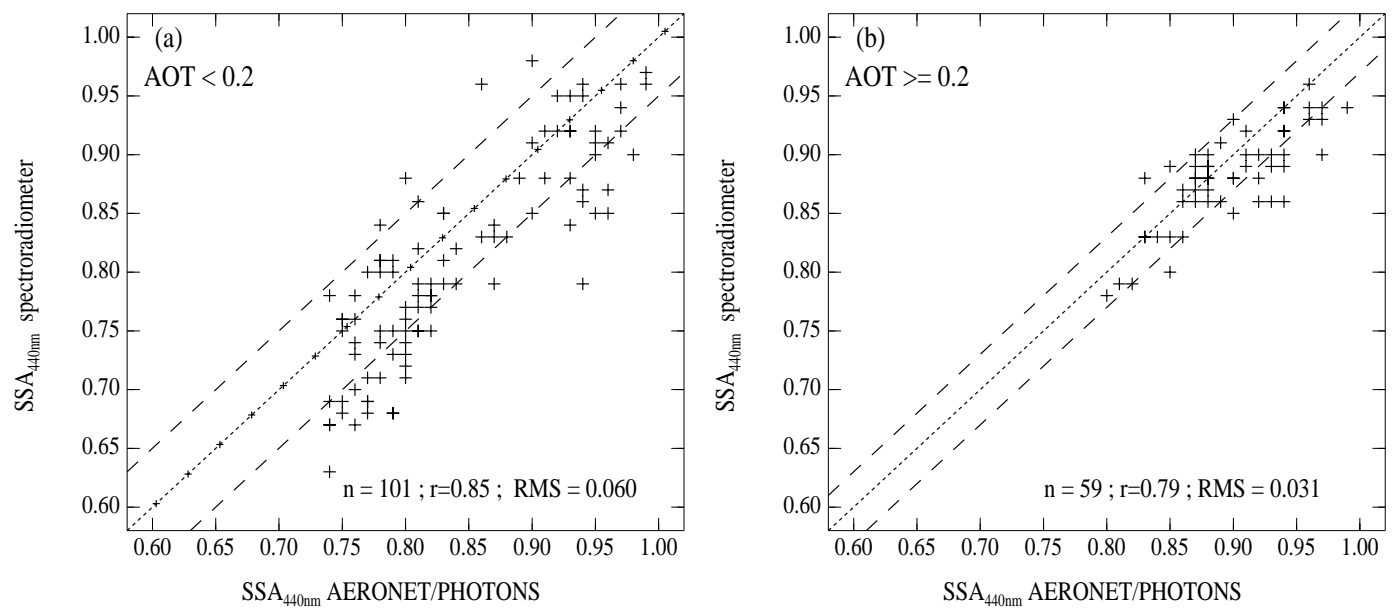

Fig. 4. Scatter plots of SSA retrieved at $440 \mathrm{~nm}$ from the spectroradiometer versus SSA from AERONET/PHOTONS for the period 20032006: (a) for AOT lower than 0.2; (b) for AOT greater than or equal to 0.2. The micro-dash line is the first bisector and dash lines are located at \pm 0.05 for AOT $<0.2$ and \pm 0.03 for AOT $\geq 0.2$, values corresponding to AERONET uncertainties. The correlation coefficient is indicated, $n$ is the number of points and RMS is the Root Mean Square of the difference (Spectro-AERONET).

variability of the 13 observations. Moreover, depending on the year, for a same month, the SSA means at a given wavelength are quite different and the spectral dependence of SSA may vary. Indeed, if we compare the months of January and September in 2003 (Fig. 6a) and in 2006 (Fig. 6b), the spectral dependence of the mean SSA are very different (January) and even opposite (September). Due to the small number of data and due to the year to year variability it is difficult to derive a seasonal pattern. Nevertheless, the SSA derived from the spectroradiometer measurements in the UV spectral range adds complementary information to that provided by AERONET/PHOTONS in the visible and near infrared, that could be use to identify the aerosol type in VDA. 

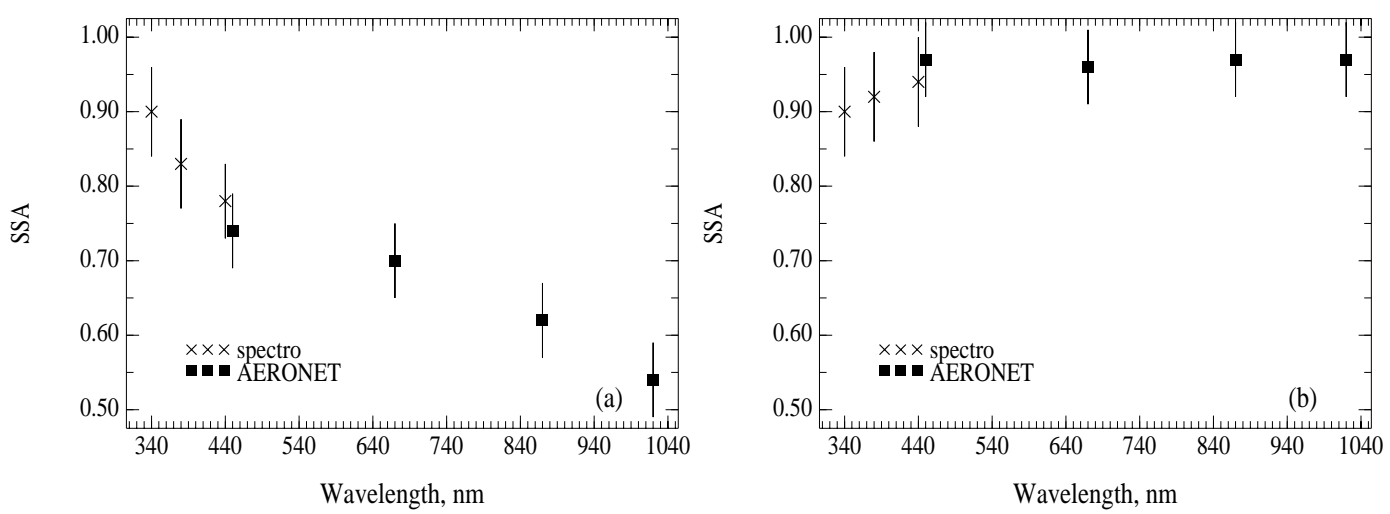

Fig. 5. Spectral variations of SSA retrieved from spectroradiometer's measurements at 340,380 and $440 \mathrm{~nm}$ (crosses) and from AERONET/PHOTONS at 440, 675, 870 and $1020 \mathrm{~nm}$ (squares): (a) 29 January 2006 at 11:00 UTC; (b) 11 September 2006 at 13:30 UTC. Vertical bars correspond to SSA uncertainties.
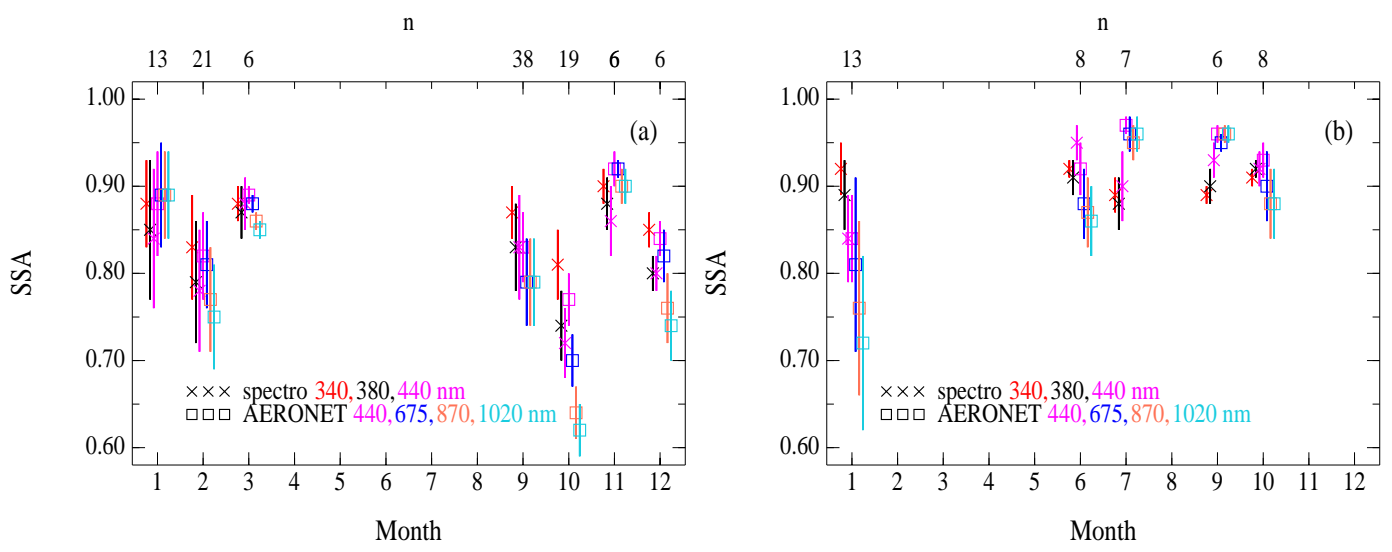

Fig. 6. Monthly means of SSA retrieved from spectroradiometer's measurements (crosses) at 340 (red), 380 (black) and $440 \mathrm{~nm}$ (magenta) and from AERONET/PHOTONS (squares) at 440 (magenta), 675 (blue), 875 (sienna) and $1020 \mathrm{~nm}$ (turquoise): (a) in 2003 ; (b) in 2006. The vertical bars represent the dispersions around the means and $n$, on the top, is the number of observations used to determine the mean. For clarity the abscissa values of the various wavelengths have been slightly shifted around the month number.

\section{Conclusions}

The global and diffuse spectral irradiance measurements performed by a spectroradiometer have been used with model calculations in order to determine the SSA in the UVvisible spectral range in VDA. The AOT obtained from ground-based spectroradiometer measurements are used as input data of the DISORT radiative transfer code to compute irradiances. Sensitivity tests show that the direct-todiffuse irradiance ratio is the best quantity to estimate the SSA with the best accuracy. Under cloudless conditions, the SSA retrieved from this quantity at $440 \mathrm{~nm}$ have been compared with SSA obtained at the same wavelength with AERONET/PHOTONS sunphotometers operating close to the spectroradiometer. The comparisons show good agreement, especially when the aerosol amount is high, i.e. when AOT are greater than 0.2. SSA retrievals at 340, 380 and $440 \mathrm{~nm}$ derived from the spectroradiometer are combined with those retrieved by sunphotometers at $440,675,870$ and $1020 \mathrm{~nm}$ in order to exhibit the spectral variations of the SSA over a large spectral range. It appears that the SSA value retrieved in VdA in the UV can be different from the one retrieved in the visible. Thus, estimating the SSA in the UV from spectroradiometer measurements leads to complementary information on the aerosol absorption already provided in the visible, that is useful for the monitoring of the aerosol in UV.

Acknowledgements. We thank L. Blarel and T. Podvin from the PHOTONS team for their help in selecting the data.

The site is supported by CNES within the french program TOSCA.

The figures were drawn using the Mgraph package developed at LOA by L. Gonzalez and C. Deroo (http: //www-loa.univ-lille1.fr/Mgraph).

Edited by: M. Wendisch 


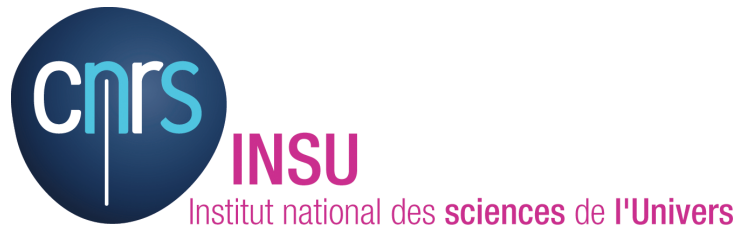

The publication of this article is financed by CNRS-INSU.

\section{References}

Arola, A., Kazadzis, S., Lindfors, A., Krotkov, N., Kujanpää, J., Tamminen, J., Bais, A., di Sarra, A., Villaplana, J. M., Brogniez, C., Siani, A. M., Janouch, M., Weihs, P., Webb, A., Koskela, T., Kouremeti, N., Meloni, D., Buchard, V., Auriol, F., Ialongo, I., Staneck, M., Simic, S., Smedley, A., and Kinne, S.: A new approach to correct for absorbing aerosols in OMI UV, Geophys. Res. Lett., 36, L22805, doi:10.1029/2009GL041137, 2009.

Bais, A. F., Kazantzidis, A., Kazadzis, S., Balis, D. S., Zerefos, C. S., and Meleti, C.: Deriving an effective aerosol single scattering albedo from spectral surface UV irradiance measurements, Atmos. Environ., 39(6), 1093-1102, 2005.

Brogniez, C., Buchard, V., and Auriol, F.: Validation of UV-visible aerosol optical thickness retrieved from spectroradiometer measurements, Atmos. Chem. Phys., 8, 4655-4663, doi:10.5194/acp-8-4655-2008, 2008.

Corr, C. A., Krotkov, N., Madronich, S., Slusser, J. R., Holben, B., Gao, W., Flynn, J., Lefer, B., and Kreidenweis, S. M.: Retrieval of aerosol single scattering albedo at ultraviolet wavelengths at the T1 site during MILAGRO, Atmos. Chem. Phys., 9, 58135827, doi:10.5194/acp-9-5813-2009, 2009.

Dubovik, O. and King, M. D.: A flexible inversion algorithm for retrieval of aerosol optical properties from sun and sky radiance measurements, J. Geophys. Res., 105(D16), 20673-20696, 2000.

Dubovik, O., Smirnov, A., Holben, B., King, M. D., Kaufman, Y. J., Eck, T. F., and Slutsker, I.: Accuracy assessments of aerosol optical properties retrieved from Aerosol Robotic Network (AERONET) Sun and Sky radiance measurements, J. Geophys. Res., 105(D8), 9791-9806, 2000.

Feister, U. and Grewe, R.: Spectral albedo measurements in the UV and visible region over different types of surfaces, J. Photoch. Photobio., 62, 736-744, 1995.

Forster, P., Ramaswamy, V., Artaxo, P., Berntsen, T., Betts, R., Fahey, D. W., Haywood, J., Lean, J., Lowe, D. C., Myhre, G., Nganga, J., Prinn, R., Raga, G., Schulz, M., and Van Dorland, R.: Changes in atmospheric constituents and in radiative forcing, in: Climate Change 2007: The Physical Science Basis, Contribution of Working Group I to the Fourth Assessment Report of the Intergovernmental Panel on Climate Change, edited by: Solomon, S., Qin, D., Manning, M., Chen, Z., Marquis, M., Averyt, K. B., Tignor, M., and Miller, H. L., Cambridge University Press, Cambridge, UK and New York, NY, USA, 129-234, 2007.

Gröbner, J., Blumthaler, M., Kazadzis, S., Bais, A., Webb, A., Schreder, J., Seckmeyer, G., and Rembges, D.: Quality assurance of spectral solar UV measurements : results from $25 \mathrm{UV}$ monitoring sites in Europe 2002 to 2004, Metrologia, 43, S66S71, doi:10.1088/0026-1394/43/2/S14, 2006.
Holben, B. N., Eck, T. F., Slutsker, I., Tanré, D., Buis, J. P., Setzer, A., Vermote, E., Reagan, J. A., Kaufman, Y. J., Nakajima, T., Lavenu, F., Jankowiak, I., and Smirnov, A.: AERONET - A federated instrument network and data archive for aerosol characterization, Remote Sens. Environ., 66, 1-6, 1998.

Houët, M.: Spectroradiométrie du rayonnement Solaire UV au sol: Améliorations apportées à l'instrumentation et au traitement des mesures, Analyse pour l'évaluation du contenu atmosphérique en ozone et en aérosols, Ph.D. thesis, Univ. of Lille, Lille, France, 2003.

Ialongo, I., Buchard, V., Brogniez, C., Casale, G. R., and Siani, A. M.: Aerosol Single Scattering Albedo retrieval in the UV range: an application to OMI satellite validation, Atmos. Chem. Phys., 10, 331-340, doi:10.5194/acp-10-331-2010, 2010.

Kazadzis, S., Gröbner, J., Arola, A., and Amiridis, V.: The effect of the global UV irradiance measurement accuracy on the single scattering albedo retrieval, Atmos. Meas. Tech., 3, 1029-1037, doi:10.5194/amt-3-1029-2010, 2010.

Krotkov, N., Bhartia, P. K., Herman, J. R., Slusser, J., Scott, G., Labow, G., Vasilkov, A., Eck, T., Dubovik, O., and Holben, B.: Aerosol UV absorption experiment (2002-04): 2. Absorption optical thickness, refractive index, and single scattering albedo, Opt. Eng., 44(4), 041005, doi:10.1117/1.1886819, 2005.

Madronich, S.: UV radiation in the natural and perturbed atmosphere. in Environmental Effects of Ultraviolet (UV) Radiation, Lewis, Boca Raton, FL, 17-69, 1993.

Petters, J. L., Saxena, V. K., Slusser, J. R., Wenny, B. N., and Madronich, S.: Aerosol single scattering albedo retrieved from measurements of surface UV irradiance and a radiative transfer model, J. Geophys. Res., 108(D9), 4288, doi:10.1029/2002JD002360, 2003.

Slaper, H., Reinen, H., Blumthaler, M., Huber, M., and Kuik, F.: Comparing ground-level spectrally resolved solar UV measurements using various instruments: a technique resolving effects of wavelength shift and slit width, Geophys. Res. Lett., 22(20), 2721-2724, 1995.

Stamnes, K., Tsay, S.-C., Wiscombe, W., and Jayaweera, K. : Numerically stable algorithm for discrete-ordinatemethod radiative transfer in multiple scattering and emitting layered media, Appl. Optics, 27, 2502-2509, 1988.

Thuillier, G., Hersé, M., Labs, D., Foujols, T., Peetermans, W., Gillotay, D., Simon, P. C., and Mandel, H.: The solar spectral irradiance from 200 to $2400 \mathrm{~nm}$ as measured by the SOLSPEC spectrometer from the ATLAS and EURECA missions, Sol. Phys., 214, 1-22, 2003.

Torres, O., Bhartia, P. K., Herman, J. R., Ahmad, Z., and Gleason, J.: Derivation of aerosol properties from a satellite measurement of backscattered ultraviolet radiation: Theoretical basis, J. Geophys. Res., 103, 17099-17110, 1998.

World Meteorological Organization, WMO: Scientific Assessment of Ozone Depletion 2006, Global Ozone Research and Monitoring Project Report No. 50, WMO, Geneva, 2007. 